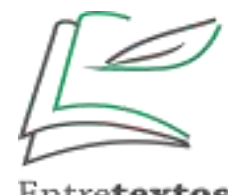

Entretextos 21(2): ago./dez. 2021

ISSN (impresso) 1519-5392

ISSN (digital) 2764-0809

DOI: $10.5433 / 1519-5392.2021 v 21$ n2.p.113

\title{
La competencia fraseológica en la enseñanza del español como lengua extranjera: una experiencia metodológica
}

\author{
Phraseological competence in the teaching of Spanish as a \\ foreign language: a methodological experience
}

\section{Competência fraseológica no ensino do espanhol como língua estrangeira: uma experiência metodológica}

Yessy Villavicencio Simón ${ }^{1}$

Ivan Gabriel Grajales Melian² https://orcid.org/0000-0001-9006-7775

https://orcid.org/0000-0002-4163-112X

RESUMEN: En los cursos de español como lengua extranjera en la Universidad de Oriente, Cuba, se evidencia una limitada interpretación del significado léxico en relación con el desarrollo de la competencia fraseológica del estudiante no hispanohablante, lo que dificulta sus posibilidades interactivas en el contexto de inmersión sociocultural, en este caso, el cubano. Por tal motivo, este artículo demuestra la sistematización de procedimientos fraseodidácticos mediante el empleo de un cuento literario: "Mercado libre", de José Soler Puig (1916-1996). Con este fin, se examinan algunos presupuestos teóricos que posibilitan al docente la comprensión e implementación de dichos procedimientos a partir de la secuencia de tareas de aprendizaje ejemplificadas (CORPAS PASTOR, 1996; SITMAN; LERNER, 1999; GÓMEZ MOLINA, 2000; RUIZ GURILLO, 2000; MADRID, 2002; AVENTÍN FONTANA, 2005; LEIBRANDT, 2006; VILLAVICENCIO SIMÓN; GRAJALES MELIAN, 2009, 2012; LÓPEZ VÁZQUEZ, 2011; ALESSANDRO, 2015; DUMBRAVESCU; MERINO MAÑUECO, 2012; PAIVA, 2019; TIMOFEEVA TIMOFEEV, 2013; SARACHO ARNÁIZ, 2015; SZYNDLER, 2015; BARRIEL GUEVARA; VILLAVICENCIO SIMÓN; FERNÁNDEZ ORTIZ, 2017; TAVARES, 2017; VILLAVICENCIO SIMÓN; TARDO FERNÁNDEZ, 2018). El análisis revela la importancia del tratamiento al cuento literario para el aprendizaje de las unidades fraseológicas como contenido apropiado para el desarrollo de la competencia fraseológica en la enseñanza del español como lengua extranjera.

\footnotetext{
1 Máster en Enseñanza del Español como Lengua Extranjera (ELE) por la Universidad de Oriente (UO), Santiago de Cuba. Doctoranda en el Programa de Posgraduación en Letras: Enseñanza de Lengua y Literatura (PPGL) por la Universidad Federal de Tocantins (UFT), Campus de Araguaína, Tocantins, Brasil. E-mail: villavicencioys69@gmail.com.

${ }^{2}$ Licenciado en Letras. Doctor en Ciencias Literarias por la Universidad de Oriente (UO), Cuba. E-mail: melian.ivan77@gmail.com.
} 
PALABRAS CLAVE: Español como lengua extranjera. Cuento literario. Competencia fraseológica.

\begin{abstract}
In the courses of Spanish as a foreign language at the Universidad de Oriente, Cuba, there is evidence of a limited interpretation of lexical meaning in relation to the development of the phraseological competence of non-Spanish-speaking students, which hinders their interactive possibilities in the context of sociocultural immersion, in this case, the Cuban context. For this reason, this article demonstrates the systematisation of phraseodidactic procedures through the use of a short story: "Mercado libre", by José Soler Puig (1916-1996). To this end, some theoretical assumptions are examined which enable the teacher to understand and implement these procedures from the sequence of exemplified learning tasks (ALESSANDRO, 2015; AVENTÍN FONTANA, 2005; BARRIEL GUEVARA; VILLAVICENCIO SIMÓN; FERNÁNDEZ ORTIZ, 2017; CORPAS PASTOR, 1996; DUMBRAVESCU; MERINO MAÑUECO, 2012; GÓMEZ MOLINA, 2000; TAVARES , 2017; LEIBRANDT, 2006; LÓPEZ VÁZQUEZ, 2011; MADRID, 2002; PAIVA, 2019; RUIZ GURILLO, 2000; SARACHO ARNÁIZ, 2015; SITMAN; LERNER, 1999; SZYNDLER, 2015; TIMOFEEVA TIMOFEEV, 2013; VILLAVICENCIO SIMÓN; GRAJALES MELIAN, 2009, 2012; VILLAVICENCIO SIMÓN; TARDO FERNÁNDEZ, 2018). The analysis reveals the importance of the treatment of the short story for the learning of phraseological units as appropriate content for the development of phraseological competence in the teaching of Spanish as a foreign language.
\end{abstract}

KEYWORDS: Spanish as a foreign language. Short story. Phraseological competence.

RESUMO: Nos cursos de espanhol como língua estrangeira da Universidad de Oriente, Cuba, há evidência de uma interpretação limitada do significado léxico em relação ao desenvolvimento da competência fraseológica do estudante não falante de espanhol, o que dificulta suas possibilidades interativas no contexto de imersão sociocultural, neste caso, cubano. Por esta razão, este artigo demonstra a sistematização dos procedimentos fraseodidáticos por meio de uso de um conto literário: "Mercado libre", do José Soler Puig (1916-1996). Para tanto, são examinado $\quad \mathrm{s}$ alguns pressupostos teóricos que permitem ao professor compreender $\mathrm{e}$ implementar esses procedimentos a partir da sequência de tarefas de aprendizagem exemplificadas (ALESSANDRO, 2015; AVENTÍN FONTANA, 2005; BARRIEL GUEVARA; VILLAVICENCIO SIMÓN; FERNÁNDEZ ORTIZ, 2017; CORPAS PASTOR, 1996; DUMBRAVESCU; MERINO MAÑUECO, 2012; GÓMEZ MOLINA, 2000; TAVARES , 2017; LEIBRANDT, 2006; LÓPEZ VÁZQUEZ, 2011; MADRID, 2002; PAIVA, 2019; RUIZ GURILLO, 2000; SARACHO ARNÁIZ, 2015; SITMAN; LERNER, 1999; SZYNDLER, 2015; TIMOFEEVA TIMOFEEV, 2013; VILLAVICENCIO SIMÓN; GRAJALES MELIAN, 2009, 2012; VILLAVICENCIO SIMÓN; TARDO FERNÁNDEZ, 2018). A análise revela a importância do tratamento do conto literário para o aprendizado de unidades fraseológicas como conteúdo apropriado para o desenvolvimento da competência fraseológica no ensino do espanhol como língua estrangeira.

PALAVRAS-CHAVE: Espanhol como língua estrangeira. Conto literário. Competência fraseológica.

\title{
Introducción
}

Los objetivos y contenidos de enseñanza esbozados en los programas actualizados de la disciplina Práctica Integral del Español como Lengua Extranjera (ELE), diseñados 
por las profesoras de español del Centro de Idiomas de la Facultad de Lenguas Extranjeras en la Universidad de Oriente, Santiago de Cuba, parten de una concepción comunicativa de la enseñanza del idioma en el aula que combina el trabajo comunicativo (nociones, funciones, temas) con la adquisición de conocimientos lingüísticos sobre diversos aspectos como la gramática, el vocabulario y la pronunciación de acuerdo con los distintos niveles de referencia. La revisión documental del programa de la disciplina para el nivel C1 revela que se enfatiza en la utilización de $\mathrm{s}$ textos literarios. Indiscutiblemente, esta tipología textual aporta datos de valor cultural, pragmático y sociolingüístico; es un referente verbal que se ofrece para el goce, la recepción estética y la formación del lector; brinda un abundante input; y añade aportaciones lingüísticas, temáticas y culturales (DUMBRAVESCU; MERINO MAÑUECO, 2012).

Sin embargo, aún en la dinámica de las clases de español como lengua extranjera en la referida institución universitaria, se otorga un insuficiente tratamiento a este tipo de texto, a pesar del reconocimiento de sus beneficios para el desarrollo de la competencia comunicativa en el estudiante no hispanohablante. En consecuencia, se manifiesta un insuficiente trabajo metodológico con los textos literarios, en particular, el cuento.

Sin lugar a dudas, el análisis de este género literario facilita el desarrollo de la competencia léxica, la competencia sociolingüística, la pragmática y la sociocultural en el proceso de enseñanza-aprendizaje de la lengua extranjera. El concepto de competencia está integrado por distintos componentes que conforman los conocimientos y las habilidades que posee y aplica una persona para comunicarse con eficacia en contextos variados, entre ellos, la competencia léxica, que el Marco Común Europeo de Referencia para las Lenguas: aprendizaje, enseñanza, evaluación (MADRID, 2002, p. 108), contempla dentro de la competencia lingüística y define como "el conocimiento del vocabulario de una lengua y la capacidad para utilizarlo, y se compone de elementos léxicos y elementos gramaticales". En otras palabras, el conocimiento se interpreta como conocimiento declarativo y la capacidad como conocimiento procedimental. Entre los elementos léxicos o unidades léxicas se encuentran por un lado, las unidades fraseológicas (UF) o unidades pluriverbales, formadas por varias palabras que se utilizan y se aprenden como un todo (fórmulas fijas, que comprenden exponentes directos de funciones comunicativas, es decir, fórmulas rutinarias, refranes, proverbios, modismos, 
frases hechas como verbos con régimen preposicional o colocaciones léxicas locuciones), y por otro, las palabras que incluyen clases abiertas de palabras (sustantivo, verbo, adjetivo, adverbio) y clases cerradas de palabras (artículos, preposiciones, conjunciones), que constituyen en sí mismas, aspectos gramaticales. De este modo, la competencia léxica posibilita al hablante reconocer la polisemia o riqueza semántica de una unidad léxica, asignarle el significado y el sentido adecuado, según el contexto de uso, atendiendo al conocimiento léxico que posee en la lengua extranjera que aprende.

La competencia sociolingüística se refiere al conocimiento de las variedades de registro de acuerdo con los factores contextuales y las normas sociales y culturales de interacción, y la competencia funcional al conocimiento de las convenciones que rigen la realización adecuada de las funciones de la lengua. La competencia sociolingüística está asociada a la competencia sociocultural, pues la enseñanza de las lenguas extranjeras no puede verse alejada del contexto sociocultural en el que se establece un vínculo entre el proceso de aprendizaje de la lengua para favorecer la comunicación y los factores que intervienen en él (AGUILERA GÁMEZ; VILLAVICENCIO SIMÓN, 2017).

La competencia pragmática se interrelaciona con el uso funcional de los recursos lingüísticos, es decir, se ocupa de la realización de los actos de habla y cómo se encadenan en la conversación o en el texto, lo que se designa también la competencia funcional. Comprende, además, la competencia discursiva y la ordenación de las oraciones y del texto (MADRID, 2002).

Por consiguiente, se considera válido presentar algunos procedimientos fraseodidácticos para el estudio de un cuento literario: "Mercado libre", del reconocido escritor santiaguero José Soler Puig (1916-1996). Con este propósito, se ejemplifica una secuencia de tareas de aprendizaje que facilitan el acercamiento a diversos contenidos (funcionales, gramaticales, léxicos, socioculturales) en la clase de ELE en la referida institución universitaria, específicamente, las unidades fraseológicas, de modo que pueda resultar de utilidad a la comunidad de profesores.

\section{Proceso de enseñanza-aprendizaje de las unidades fraseológicas en ELE: procedimientos fraseodidácticos.}

El aprendizaje del idioma incluye su fraseología en tanto es reflejo de una comunidad cultural de habla concreta, de la cual se nutre el uso reiterativo de las 
unidades fraseológicas por parte de los hablantes en la comunicación interpersonal. Dadas sus particularidades de uso e interpretativas, ligadas a los valores específicos y diferenciados de una lengua nacional como realidad dinámica e irregular, resulta representativa su condición idiosincrásica, lo cual supone que reflejen la identidad de una colectividad e inciden en la comunicación intercultural (MARTÍ SÁNCHEZ, 2005).

Dentro del campo de la Didáctica de Lenguas (Glotodidáctica), surge la Fraseodidáctica o Didáctica de la fraseología, cuyo objetivo consiste en estudiar el desarrollo de la competencia fraseológica desde un enfoque intralingüístico e interlingüístico como parte esencial de la competencia comunicativa de un hablante en el proceso de enseñanza-aprendizaje (ALESSANDRO, 2015). La competencia fraseológica forma parte de la competencia léxica y la competencia comunicativa; se define como la habilidad de adecuar las diferentes unidades fraseológicas de una lengua al texto, al contexto, la relación con el interlocutor, las normas sociales y la intención comunicativa (ALESSANDRO, 2015; SARACHO ARNÁIZ, 2015; SZYNDLER, 2015; TIMOFEEVA TIMOFEEV, 2013; TAVARES, 2017; VILLAVICENCIO SIMÓN; TARDO FERNÁNDEZ, 2018). Ello incide en su conceptualización como habilidad para reconocer y producir las UF, es decir, entendida así no solo por competencia fraseológica receptiva, sino además, como competencia fraseológica productiva, o sea, para producir enunciados fraseológicamente adecuados (LÓPEZ VÁZQUEZ, 2011).

De acuerdo con SARACHO ARNÁIZ (2015), los docentes no le otorgan un lugar relevante en el aula, puesto que poseen una insuficiente formación teórica para reconocer los límites del ámbito fraseológico. La adquisición de dicha competencia constituye un aspecto problemático dada las complejas peculiaridades formales y semánticas de las UF (alto grado de fijación e idiomaticidad) y la ausencia de referencias claras acerca de los tipos de unidades que deben trabajarse en los distintos niveles de enseñanza (LÓPEZ VÁZQUEZ, 2011; SZYNDLER, 2015), sobre todo, las UF idiomáticas que aportan significados amplios (SARACHO ARNÁIZ, 2015).

Por estas razones, el análisis exhaustivo de las diversas UF se reserva para los niveles superiores B2 (Nivel Avanzado), C1 (Nivel de Dominio Operativo Eficaz) y C2 (Nivel de Maestría), puesto que los estudiantes han alcanzado cierto nivel de competencia comunicativa que les permite captar los sentidos de las UF y usarlas en contextos lingüísticos apropiados (LÓPEZ VÁZQUEZ, 2011; MADRID, 2002). En esta misma línea, 
Madrid (2002) solo incluye las UF en los niveles superiores del conocimiento de una lengua, sin definir los tipos que resultan más convenientes enseñar en cada nivel, aunque confiere libertad al docente para hacerlo en otros niveles y no señala la competencia fraseológica. Plantea que el estudiante de un nivel C1 "tiene un buen dominio de un repertorio léxico muy amplio, que incluye expresiones idiomáticas y coloquiales", y en el nivel C2 debe demostrar poseer un "buen dominio de expresiones idiomáticas y coloquiales" (MADRID, 2002, p. 109). Es por ello que las unidades fraseológicas comienzan a formar parte del bagaje lingüístico de los hablantes de lenguas extranjeras en el nivel intermedio avanzado (B2). Según SARACHO ARNÁIZ (2015, p. 156), "los criterios de inclusión de las UF en los niveles más elevados ( $\mathrm{C} 1$ y C2) es un error didáctico que se propicia por no establecerse un contexto teórico fraseológico coherente."

La sistematización realizada en cuanto a las investigaciones sobre las unidades fraseológicas desde la Fraseodidáctica, posibilita destacar que un factor clave que dificulta el proceso de enseñanza-aprendizaje de ellas es tanto el nivel de de codificación del significado fraseológico como el nivel de producción lingüística, en el que el alumno tiene que emplear de forma apropiada este tipo de unidad léxica en correspondencia con las situaciones comunicativas concretas (SZYNDLER, 2015). En ciertas ocasiones, se les otorga un tratamiento elemental y tradicionalista pues aparecen en la clase, pero de forma accidental, sin una planificación didáctica. Por ende, las acciones didácticas manifiestan el empleo de procedimientos, estrategias y métodos poco coherentes.

Las investigaciones actuales ponen de relieve la contribución de una gran variedad de concepciones que promueven el tratamiento al componente fraseológico como contenido para ampliar la competencia léxica en lenguas extranjeras (ALESSANDRO, 2015; CORPAS PASTOR, 1996; GÓMEZ MOLINA, 2000; LÓPEZ VÁZQUEZ, 2011; RUIZ GURILLO, 2000; SARACHO ARNÁIZ, 2015; TIMOFEEVA TIMOFEEV, 2013; VILLAVICENCIO SIMÓN; GRAJALES MELIAN, 2009, 2012; VILLAVICENCIO SIMÓN; TARDO FERNÁNDEZ, 2018). No obstante, los fines de los estudios relacionados con el proceso de enseñanza y aprendizaje de las UF difieren, pues se centran en su tratamiento sin profundizar en los procedimientos fraseodidácticos necesarios para una sistematización integradora de la formación de la competencia léxica que favorezca la dinámica de este tipo de unidad léxica en la didáctica de lenguas extranjeras.

Si bien se reconoce la importancia de los modelos didácticos aportados 
(ALESSANDRO, 2015; GÓMEZ MOLINA, 2000; SARACHO ARNÁIZ, 2015; TIMOFEEVA TIMOFEEV , 2013), se manifiestan limitaciones en cuanto a la inclusión de todos los tipos de UF, pues se circunscriben especialmente a la didáctica de las locuciones, colocaciones y fórmulas rutinarias; la atención que reservan a los refranes y los modismos como componentes del repertorio fraseológico es más bien escasa, y no especifican los niveles comunes de referencia en los que resulta apropiada su enseñanza.

El modelo del heptágono para la enseñanza del léxico propuesto por Gómez Molina (2000) es un referente teórico-metodológico para la fundamentación de modelos didácticos de la enseñanza de unidades fraseológicas que incluye aspectos lingüísticos y didácticos esenciales para su tratamiento. Se adoptan los presupuestos teóricos que sustentan el modelo elaborado por este autor: lingüísticos (la estructura del léxico, formación de palabras y relaciones léxicas de significado como sinonimia, antonimia y polisemia presentes en muchas UFS); etnolingüísticos (dimensión cultural); sociolingüísticos (variedades sociales, contextos diferentes); psicolingüísticos (desarrollo de la interlengua, es decir, la lengua en proceso de formación); cognitivos (conocimiento a través del lexicón y del almacenamiento de unidades); y de lingüística aplicada (enseñanza-aprendizaje del léxico y de la fraseología).

La propuesta de Gómez Molina (2000) comprende, además, la interrelación directa de varias fases complementarias, centradas en los ejes operativo e interpretativo. Primeramente, se realiza la presentación de una determinada UF, en la cual se tienen en cuenta la observación, el análisis y la inducción (fase operativa). Luego se pasa a la comprensión o interpretación en la que son fundamentales la hipótesis, la producción y la experimentación (fase receptiva). Este proceso se complementa con la utilización y sistematización donde el estudiante generaliza (fase reproductiva) para sucesivamente memorizar y conceptualizar (fase de control). La deducción, la retención y la recapitulación o consolidación mediante nuevas aplicaciones son esenciales en la última etapa (fase de transferencia).

Siguiendo las aportaciones de Gómez Molina (2000), la autora Saracho Arnáiz (2015) presenta un Modelo Metodológico del Heptágono (MMH) basado en el enfoque comunicativo e integra las aportaciones de la lingüística cognitiva y el enfoque léxico con el objetivo de desarrollar la competencia fraseológica explícita en ELE, teniendo en cuenta el tratamiento didáctico a las locuciones. Dicho modelo consta de siete fases, la primera 
consiste en los referentes cuyo objetivo es actualizar los conocimientos previos del alumno y activar el mapa conceptual a partir de las actividades de entrada con textos audiovisuales como noticias, titulares, anuncios publicitarios, debates televisados, y textos literarios que permiten acercar al estudiante al significado contextual de las UF y relacionarlas con otras unidades léxicas y fraseológicas. El segundo paso metodológico es la presentación de las UF y su significado unitario mediante actividades centradas en asociaciones por nociones (relaciones paradigmáticas) y funciones gramaticales (relaciones sintagmáticas) por escrito. La tercera consiste en las relaciones semánticas de sinonimia, polisemia y antonimia.

Como cuarta fase se plantea la fraseogénesis a partir de actividades que facilitan el aprendizaje de la estructura y productividad/motivación de la unidad. La quinta se refiere a los niveles de uso o registro que se centra en actividades sobre los contextos de uso de las UF; la sexta consiste en el significado fraseológico mediante actividades de explotación de la imagen y del sentido metafórico; y como séptimo paso se encuentra la generalización que es la fase de producción activa que engloba a las anteriores y se desarrollan tareas de producción de textos escritos y orales para aplicar las unidades fraseológicas trabajadas, principalmente en contextos orales interactivos como evaluación de toda la secuencia de aprendizaje (SARACHO ARNÁIZ, 2015). En consecuencia, se asumen estos procedimientos metodológicos para elaborar actividades de fraseodidáctica de manera coherente, al tener en cuenta la estructura lingüística de las UF, su aspecto cultural, y también los aspectos psicológicos y didácticos del proceso de enseñanza-aprendizaje.

Alessandro (2015) aporta un Modelo Fraseológico Pragmático (Mo. Fra. P.) dentro del marco de la investigación-acción educativa, con un enfoque orientado a la acción y una perspectiva interaccional de la enseñanza y aprendizaje de la lengua. Se centra en las características de las unidades fraseológicas pragmáticas (UFP) pscicosociales que influyen en la interacción oral conversacional de registro coloquial y favorecen el desarrollo de la competencia fraseológica definida como subcompetencia transversal de la competencia comunicativa, atendiendo a la integración de forma holística de los aspectos lingüístico, sociolingüístico, pragmático y sociocultural desde un enfoque integrador que privilegia la dimensión pragmática e interactiva.

Como bien Defiende Timofeeva Timofeev (2013), el significado de las unidades 
fraseológicas depende del enunciado en el cual se insertan, de ahí que el análisis del funcionamiento comunicativo de este tipo de unidad debe realizarse dentro de una secuencia textual, a partir de la presentación articulada y sistematizada de las distintas informaciones que configuran el significado fraseológico tanto en el nivel semántico como el nivel pragmático. Se trata de diseñar actividades destinadas a formar la capacidad del alumno de identificar, comprender y explicar las unidades fraseológicas en un texto. En tal sentido, la autora subraya: "[...] la explicación del significado de una UF [...] le confiere una ordenación y sistematización que actúan como un procedimiento mnemotécnico, con lo cual el estudiante consigue solventar mejor las diversas aristas formales y semánticas que presentan algunas UF" (TIMOFEEVA TIMOFEEV, 2013, p. 332).

No obstante, si bien se reconoce la significatividad de estos procedimientos fraseodidácticos, se consideran insuficientes para desarrollar la competencia fraseológica en el estudiante de español como lengua extranjera, pues conducen a un tratamiento reduccionista a las unidades fraseológicas que impide un mayor nivel de sistematización e interpretación acorde con su funcionalidad en los distintos contextos de uso de la lengua extranjera. Por tal motivo, se advierte la necesidad de revelar la sistematización de procedimientos fraseodidácticos con el fin de optimizar la formación de la competencia fraseológica en el alumno no hispanohablante. A efectos del referido objetivo, se expone una secuenciación de tareas sobre la base de cuatro fases de identificar, comprender, consolidar y usar las UF para la modelación de una dinámica fraseológica, teniendo en cuenta el uso del cuento literario seleccionado en las clases de español como lengua extranjera para un nivel común de referencia $\mathrm{C} 1$.

\section{El uso del texto literario: un acercamiento al cuento "Mercado libre" de José Soler Puig}

En la enseñanza de lenguas extranjeras, se incorpora el texto literario como tipología textual, pues cumple las funciones de estímulo, vehículo y herramienta para la adquisición de la competencia comunicativa, en sus componentes lingüísticos y culturales, en tanto despierta el interés por el mundo cultural de la lengua meta y el placer por la lectura en dicha lengua que estimula la comunicación (SITMAN; LERNER, 1999). De ello se infiere la relevancia de la formación de la competencia literaria en el alumno, la cual comprende tanto saberes, habilidades y estrategias, como criterios valorativos sobre la 
significación cultural y artística del texto, lo cual supone la formación para la recepción lectora, el reconocimiento y análisis del discurso literario, y la aplicación y producción de discurso (MENDOZA, 2001 citado por DUMBRAVESCU; MERINO MAÑUECO, 2012).

Existe un gran número de estudios que enfatizan en las ventajas del uso del cuento literario como un recurso didáctico adecuado para desarrollar la competencia comunicativa en el proceso de enseñanza-aprendizaje del español como lengua extranjera (DUMBRAVESCU; MERINO MAÑUECO, 2012; SITMAN; LERNER, 1999; VILLAVICENCIO SIMÓN; GRAJALES MELIAN, 2009). El tratamiento a este género literario en el ámbito de la didáctica de ELE con un enfoque comunicativo, ha cobrado una marcada importancia debido a que es una narración de breve extensión que posibilita la planificación de múltiples tareas didácticas a partir de la inclusión de contenidos socioculturales, léxicos, funcionales y gramaticales de forma integrada. El control y la ejecución de dichas tareas implican la práctica de las destrezas en el proceso de aprendizaje del español. Así, el análisis y comentario del cuento exige la interacción comunicativa entre el profesor y el estudiante, de modo que el texto pueda explotarse en el proceso de comprensión e interpretación, que depende del sentido que adquieren las expresiones lingüísticas en situaciones contextualizadas y re-presentadas en el lenguaje literario connotativo.

Las características del cuento literario (brevedad, pocos personajes y conflictos, reducción del marco espacio - temporal) facilitan el proceso de comprensión lectora, el cual se efectúa en dos niveles: el nivel textual (se observan las diversas estructuras del texto) y el nivel contextual (se relacionan las descripciones estructurales con diferentes propiedades del contexto, los procesos cognitivos y las representaciones o factores socioculturales). El texto como tejido de significación que obedece a reglas estructurales, semánticas y pragmáticas, interactúa con el lector en el proceso de comprensión en busca de la construcción de sentido.

La comprensión está influida por los conocimientos previos del receptor y las características propias del texto. En este sentido, es imprescindible poseer una competencia lectora debido a que cuando se lee un texto del cual ya se conoce algo, esto favorece su comprensión. Los lectores competentes aplican automáticamente procedimientos, estrategias y técnicas de su lengua materna en textos de lengua extranjera. Y aunque cada lector pueda ser consciente de su proceso de comprensión y 
de los procedimientos que utiliza en la práctica de dicha actividad, de manera simultánea se ponen en juego informaciones de tipo léxico, sintáctico y semántico, las cuales colaboran con el objeto de reconstruir el significado más viable del texto.

Por consiguiente, para lograr la comprensión del texto es importante tanto el conocimiento de su contexto histórico como determinados aspectos de la personalidad del autor. De esta manera, el estudiante puede modificar y/o confirmar sus perspectivas ideológicas sobre la realidad que el texto literario representa y compararla con la cultura de la cual es portador. A nuestro modo de ver, la aproximación a la figura del narrador José Soler Puig (Premio Nacional de Literatura, 1986) contribuye a promover la literatura producida por autores santiagueros de notable reconocimiento en el ámbito hispanoamericano, en ocasiones un tanto desconocida por los estudiantes interesados en el aprendizaje de la lengua y la literatura en español.

Cabe enfatizar que en el cuento "Mercado libre" publicado en 1961, el escritor muestra por primera vez la denuncia social como eje temático de su cuentística, anticipando personajes y conflictos de su novela El pan dormido (1975), relacionados con la sociedad cubana antes del triunfo de la revolución, acontecido el primero de enero de 1959. Los conflictos presentados adquieren relevancia para la interpretación de las connotaciones socioculturales de la modalidad cubana del español a partir de la explicación acerca de las diferencias de registros coexistentes en el texto, las cuales inciden en el conocimiento léxico de la lengua meta. En este ámbito, el profesor se convierte en un interlocutor más que interviene como facilitador para esclarecer dificultades sintácticas y léxicas o para explicitar cuestiones del comentario literario y detalles típicos de la cultura meta.

Se concuerda con las investigadoras Dumbravescu; Merino Mañueco (2012) en que el texto literario puede aportar los registros lingüísticos, funcionales, estratégicos, discursivos, socioculturales y sociolingüísticos necesarios para la clase de ELE. Al respecto, argumentan:

[...] Al leer textos literarios, los estudiantes tienen que hacer frente a un lenguaje pensado para hablantes nativos $y$, de este modo, adquieren una mayor familiaridad con una gran variedad de usos lingüísticos, de formas y de convenciones de la lengua escrita [...] la literatura no puede menos que incorporar una gran cantidad de información cultural (COLLIE; SLATER, 1987, p. 3 citado por DUMBRAVESCU; MERINO MAÑUECO, 2012, 
p. 41).

La secuencia de tareas de aprendizaje que se ofrece para el análisis del cuento "Mercado libre", del reconocido narrador santiaguero José Soler Puig (1916-1996) resulta una opción metodológica que puede propiciar el acercamiento sociocultural al tema del pregón como rasgo identitario del acervo popular tradicional en el entorno donde está inmerso el estudiante no hispanohablante de los cursos de ELE, en nuestro caso, en la ciudad de Santiago de Cuba. El estudio de los aspectos socioculturales es un elemento que aún en la actualidad, necesita de un mayor nivel de profundización en situación de inmersión, para ampliar el conocimiento de las costumbres, las tradiciones y creencias, así como la literatura, la música, entre otras cuestiones de índole lingüística y sociocultural. En los cursos de español como lengua extranjera en esta institución de educación superior, se incluyen contenidos socioculturales mediante el empleo de diversas tipologías textuales, que brindan a los estudiantes la posibilidad de conocer y comprender el medio lingüístico y cultural cubano donde se encuentran inmersos debido a cuestiones académicas, laborales o familiares (SOCORRO, 2005).

\section{Metodología}

A partir de las entrevistas a los docentes de los cursos de español como lengua extranjera en la Universidad de Oriente, la revisión documental de los programas y la observación a clases, se pudo determinar un insuficiente tratamiento didáctico a las unidades fraseológicas que limita el desarrollo de la competencia fraseológica en el estudiante no hispanohablante. El estudio se basa en el enfoque hermenéutico-dialéctico, el cual favoreció la observación e interpretación para profundizar en los rasgos distintivos y la complejidad del proceso de enseñanza y aprendizaje de este tipo de unidades léxicas en el contexto citado.

La revisión bibliográfica de la literatura científica sobre la temática, permitió examinar algunos presupuestos teóricos que posibilitan al docente la comprensión e implementación de los procedimientos fraseodidácticos a partir de la secuencia de tareas de aprendizaje ejemplificadas (ALESSANDRO, 2015; AVENTÍN FONTANA, 2005; BARRIEL GUEVARA; VILLAVICENCIO SIMÓN; FERNÁNDEZ ORTIZ, 2017; CORPAS PASTOR, 1996; DUMBRAVESCU; MERINO MAÑUECO, 2012; GÓMEZ MOLINA, 2000; TAVARES, 2017; LEIBRANDT, 2006; LÓPEZ VÁZQUEZ, 2011; MADRID, 2002; PAIVA, 2019; RUIZ GURILLO, 2000; SARACHO ARNÁIZ, 2015; SITMAN; LERNER, 1999; SZYNDLER, 2015; TIMOFEEVA 
TIMOFEEV, 2013; VILLAVICENCIO SIMÓN; GRAJALES MELIAN, 2009, 2012; VILLAVICENCIO SIMÓN; TARDO FERNÁNDEZ, 2018).

La propuesta didáctica constituye una síntesis práctica de la experiencia profesional como docente en la disciplina de español como lengua extranjera en el segundo semestre del curso académico 2016-2017 en la Universidad de Oriente. Está dirigida a aquellos estudiantes que desean alcanzar el nivel de referencia de usuarios competentes ( $\mathrm{C} 1)$. Consiste en el desarrollo de una clase de lectura con énfasis en el tratamiento a las unidades fraseológicas para ampliar el conocimiento léxico en la lengua española y, por ende, mejorar la competencia fraseológica de los estudiantes. Se sugieren actividades de comprensión lectora a partir del cuento literario con la intención de interpretar, opinar, valorar, reflexionar y comparar sobre la temática del texto.

\section{Análisis}

Seguidamente, se presentan algunas de las tareas de aprendizaje y los contenidos socioculturales, los contenidos funcionales, los contenidos léxicos y los contenidos gramaticales. Esta contribución puede ampliarse o modificarse según los objetivos de aprendizaje para optimizar la explotación didáctica de dichos contenidos con la lectura analítica del cuento.

\section{Experiencia didáctica}

Contenidos socioculturales: el pregón como tradición oral desde el contexto cubano; el regateo del precio.

Contenidos funcionales: narrar situaciones del pasado; manifestar acuerdo y desacuerdo; compartir pena o decepción; valorar experiencias; expresar estados de ánimo; manifestar advertencia.

Contenidos léxicos: fórmulas rutinarias del registro coloquial y locuciones. Contenidos gramaticales: pretérito indefinido, pretérito perfecto y pretérito pluscuamperfecto del modo indicativo. Usos, alternancia y oposición entre estos tres tiempos verbales. Verbos cuyos participios son irregulares. (fase de profundización y consolidación)

\section{Actividad de precalentamiento (prelectura)}

a) Relacione el significado que corresponde a cada una de las siguientes expresiones coloquiales.

1. jabas de yarey

2. pilas de naranjas hombres sucios, descuidados

_invitación para comprar 
3. todo desparramado

4. hombres puercos

5. ivenga marchante!

6. quince quilos

7. nariz remangada

8. muerto de hambre

9. el acabóse

10. le dio una galleta

11. el regateo del precio

12. Ojalá que...

13. un real

b) ¿Qué le sugiere el título del cuento: "Mercado libre"?

bolso de fibra vegetal

persona orgullosa

muchas naranjas

diez centavos

desear que...

desorganizado, regado

quince centavos

un gran problema

_pedir rebaja de precio

persona muy humilde

dar una bofetada en la cara

\section{Actividad durante la lectura}

a) Responda las siguientes preguntas de acuerdo con el texto:

- Describa los personajes.

- ¿Qué relación se establece entre los personajes?

- ¿Qué situación de las que aparecen en el cuento le gustó más? Explique.

b) Extraiga del texto expresiones que refleja $\mathrm{n}$ acuerdo, desacuerdo, pena, sorpresa o asombro.

Lea el siguiente resumen del cuento "Mercado libre" del escritor santiaguero José Soler Puig.

Él había venido con mamá. También había venido Tita, la cocinera, larga y flaca, que parecía que nunca se peinaba...

Tita se bajó, con las dos jabas de yarey colgadas del brazo (...). En la Plaza de Marte, llena de mujeres con paquetes y sin paquetes, entre montones de malangas y boniatos, racimos de plátanos y guineos, cajas de huevos, pilas de naranjas y mandarinas, berro y lechuga, tomates, pollos y gallina atados por las patas, todo desparramado en el suelo, muchos hombres puercos - mamá le decía "puerco", cuando se ensuciaba la ropa - voceaban su mercancía.

iVeinte huevos una peseta! iVenga, marchante! iAquí! iVeinte por peseta!

iUna lata de boniato, quince kilos!

iRaspadura de miel!

iMire el queso del país! iCinco centavos la libra!

iRaspadura de miel!

Las voces parecían de gente que se quiere fajar, pero un poco cansadas, como si llevaran mucho rato gritando su guapería. Los hombres tenían la cara larga - cara de negro, cara de blanco, cara de mulatos -, sin una sonrisa, sobre los hombros de camisas mugrientas, rotas, llenas de parches. A casi todos los individuos les colgaba un machete al cinto, en viejas fundas de cuero. Había en la plaza como un aletear de grandes palomas turbias que volaban al ras del suelo.

Este racimo, iquince centavos! iQuince centavos! iQuince centavos!

-Ofrécele un real, Tita - dijo mamá.

-Un real- le dijo Tita al hombre de los guineos.

- iQuince centavos! - pregonó el de los guineos, mirando a Tita.

-Un real- insistió mamá. 
-Un real- repitió Tita.

- iQuince centavos! - volvió a pregonar el hombre.

- Déjalo entonces Tita- dijo mamá, y agregó muy bajito- ¿Qué se habrá figurado este muerto de hambre?

El hombre de los guineos, que tenía machete al cinto, podía haber oído a mamá y entonces... Pero el guajiro volvió a su pregón, ya sin fijarse en Tita.

iQuince centavos! iQuince centavos!

Mamá le dijo al chofer... que echara a andar la máquina, y se movieron media cuadra, muy despacio. Tita seguía a pie, por la acera.

- ¿A cómo? - preguntó Tita al mulato que vendía pollos.

-Según- respondió él- Estos, medio peso los dos- y levantó hasta la cabeza las aves, ...

-Cuarenta centavos- dijo mamá con la nariz remangada.

-Cuarenta centavos- le repitió Tita al pollero.

-No- dijo el mulato. $Y$ tiró los pollos al suelo... todo.

- Hemos venido muy temprano - dijo mamá- todavía piensan que van a venderlo

El chofer pensaba en el racimo de los grandes guineos. Sacó la cabeza por la ventanilla y vio que donde antes había estado la máquina había un remolino de gente . Una figura amarilla se acercaba, a grandes zancadas, blandiendo, sobre el sombrero de castor, el machete, ...

El grupo se abrió, ... Quedó en el centro, inmóvil, un sombrero de yarey sobre una camisa azul sostenida por unos pantalones desteñidos...

Tita corría hacia el molote. El machete cayó sobre el sombrero de yarey y la camisa azul... allí debajo había un hombre.

Al fin, el machete se inmovilizó, a lo largo de la pierna amarilla. El soldado levantó con una mano la camisa...

Tita llegó corriendo hasta la máquina... resoplaba.

- iCómo te gustan los líos, Tita! - dijo mamá- ¿A ti qué te importaba?

-Para que no me cuenten, señora - contestó Tita, ... - Hay que ver.

- ¿Y qué pasó? - preguntó mamá -

- El acabóse, señora - respondió Tita- Un guajiro le dio una galleta a una señora.

- i¿Cómo?!- dijo mamá.

-Sí, señora. Una galleta - dijo Tita.

- ¿Pero cómo se atrevió? - Preguntó mamá- iQué atrevido! ¿Y por qué cometió esa barbaridad el guajiro?

-Parece que la señora dijo algo malo del racimo de guineo, y el guajiro se incomodó. Y le soltó la mano - explicó Tita.

- iQué animal! timón.

-No fue una galleta, señora - dijo el chofer que había vuelto a sentarse frente al

- ¿No fue una galleta?

-No, señora. Fue un empujón. La señora quiso llevarse el racimo de guineo por un real... Le echó mano para meterlo en la máquina. El guajiro, tal vez sin darse cuenta, le dio un empujón... Era natural que tratara de defender su racimo.

Mamá y Tita habían cambiado desde la llegada del chofer. A mamá se le había quitado la apretazón de la cara y Tita parecía triste y cansada, como cuando mamá le decía que no le había quedado bueno el fricasé, que no le había echado sal a la 
ensalada.

El hombre de los pollos, que no había querido venderlos en cuarenta centavos, apareció junto a Tita.

-Está bien- dijo-. Cójalos en cuarenta centavos. Hablaba como si no hubiera pasado tanto rato del regateo del precio.

- Treinta centavos- le dijo mamá a Tita, con voz bajita.

-Cójalos- dijo el hombre, ...

Tita le dio el dinero y metió los pollos en la máquina. Ahora el mercado libre estaba lleno de excitación, ....

-Vamos por los guineos- ordenó mamá.

-Pero si ese hombre fue el que se llevaron- dijo Tita.

- ¿Y qué? Alguien tiene que haber quedado en su lugar. Vamos...

El chofer dio marcha atrás y Tita caminó por la acera. El racimo estaba en su lugar con otro hombre al pie...

-Esos guineos - dijo Tita...

-Un real - dijo el hombre

-Un medio - dijo mamá.

-Sí - dijo el nuevo hombre de los guineos.

Y él mismo cargó el racimo y lo metió en la máquina.

Le dieron dos vueltas a la plaza... Tita compró de todo con los precios que mamá ponía: habichuelas, huevos, lechuga, rábanos, plátanos verdes y maduros, otros cinco pollos... Tita llenó las dos jabas... al fin, mamá dijo:

-Está bueno. ¿Cuánto se ha gastado? -preguntó mamá.

-Usted me dio cinco pesos... me quedan dos pesos y un medio.

- iMagnífico! -dijo mamá- iMenos de tres pesos! Es como un milagro.

Mamá miró las jabas que Tita había puesto a su lado en el asiento del chofer. Él sabía que mamá estaba contenta.

-Esto del mercado libre ha sido una buena idea del gobierno- dijo mamá-...

Tita ni el chofer dijeron nada. Mamá siguió hablando:

- Hoy hemos comprado tres veces más que otro día, y con menos dinero... Ojalá que el viernes se dé otra bronca...

\section{Actividad de post-lectura}

a) ¿Qué expresiones utilizaría para reaccionar ante las siguientes situaciones?

- Te acabas de enterar que un amigo muy querido murió en un accidente automovilístico.

- Te enteras que un amigo defiende satisfactoriamente su Tesis Doctoral.

- Un familiar cercano es promovido en su cargo laboral y ascendió salarialmente.

- Te despiertas y descubres que te han robado en la casa.

- Quieres viajar mañana pero no puedes, porque te han dicho que tienes una reunión urgente ese mismo día con tu jefe.

\section{Conclusiones}

De lo expuesto se concluye que los referentes teóricos y metodológicos aportados indican la pertinencia del uso del cuento literario "Mercado libre" del narrador santiaguero 
José Soler Puig en la enseñanza del español como lengua extranjera, con el fin de mejorar la competencia fraseológica en el estudiante no hispanohablante de un nivel de referencia C1 y al mismo tiempo, promover el conocimiento de escritores representativos de la literatura hispanoamericana, en este caso, cubana. El tratamiento didáctico a esta tipología textual posibilita una adecuada integración de actividades y contenidos en el aprendizaje que favorecen, además, la competencia comunicativa del alumnado.

A pesar de que los distintos modelos didácticos facilitan la enseñanza de las unidades fraseológicas, no incorporan todos los tipos de UF pues se circunscriben especialmente a la didáctica de las locuciones, colocaciones y fórmulas rutinarias; la atención que reservan a los refranes y los modismos como componentes del repertorio fraseológico es más bien escasa, y no especifican los niveles comunes de referencia. Por este motivo, el proceso de enseñanza-aprendizaje del léxico aún requiere de un mayor nivel de profundización desde lo didáctico, en el que se resignifiquen de manera coherente, los rasgos distintivos de la competencia fraseológica para el desarrollo de la dinámica de las UF en cada nivel de dominio por el que transita el alumno de ELE.

El análisis de los distintos procedimientos fraseodidácticos resultan esenciales para la elaboración de la secuencia de tareas de aprendizaje que enfatizan en el proceso de enseñanza-aprendizaje de las unidades fraseológicas como contenido fundamental para enriquecer las competencias léxica, pragmática, sociolingüística y sociocultural. En síntesis, dicha secuencia permite orientar la planificación sobre el estudio sistemático de este tipo de unidades sobre la base de cuatro fases de identificar, comprender, consolidar y usar las UF para la modelación de una dinámica fraseológica específicamente, en los cursos de ELE en el contexto de la Universidad de Oriente, Santiago de Cuba.

\section{Referencias}

AGUILERA GÁMEZ, Y.; VILLAVICENCIO SIMÓN, Y. Tratamiento didáctico del registro coloquial para el desarrollo de la competencia sociolingüística en el nivel elemental de ELE. In: MUÑOZ ALVARADO, A.; RUIZ MIYARES, L. C.; ÁLVAREZ SILVA, M. R. Nuevos estudios sobre comunicación social. Santiago de Cuba: Centro de Lingüística Aplicada, 2017. v. 2, p. 533-536.

ALESSANDRO, A. Didáctica de la fraseología: una experiencia desde el marco de la investigación en la acción educativa. Zona Próxima, [s. I.], n. 22, p. 172-192, enero/jun. 2015. Disponible en: http://rcientificas.uninorte.edu.co/index.php/zona/article/viewArticle/6065/7743. 
Accedido el: 20 abr. 2018.

AVENTÍN FONTANA, A. El texto literario y la construcción de la competencia literaria en E/LE: un enfoque interdisciplinario. Espéculo. Revista de Estudios Literarios, Madrid, $\mathrm{n}$. 29, marzo/jun. 2005. Disponible en:

http://www.ucm.es/info/especulo/numero29/textele.html. Accedido el: 12 oct. 2007.

BARRIEL GUEVARA, M. T.; VILLAVICENCIO SIMÓN, Y.; FERNÁNDEZ ORTIZ, I. La enseñanza y el aprendizaje del vocabulario en las clases de español como lengua extranjera en situación de inmersión sociocultural. Santiago, Santiago de las Vegas, p. 137-149, 2017. Número especial. Disponible en:

https://santiago.uo.edu.cu/index.php/stgo/article/view/2583. Accedido el: 6 sept. 2018.

CORPAS PASTOR, G. Manual de fraseología española. Madrid: Editorial Gredos, 1996.

DUMBRAVESCU, D.; MERINO MAÑUECO, S. El Camino: actividades prácticas para la clase de ELE. Boletín de la Asociación para la Enseñanza del Español como Lengua Extranjera, La Rioja, n. 46, p. 41-49, mayo, 2012.

GÓMEZ MOLINA, J. R. Las unidades fraseológicas del español: una propuesta metodológica para la enseñanza de las locuciones en la clase de ELE. In: COPERÍAS, M. J.; REDONDO, J.; SANMARTÍN, J. (ed.). Aprendizaje y enseñanza de una segunda lengua: quaderns de filologia. València: Universitat de València, 2000, p. 111-134.

LEIBRANDT, I. El aprendizaje intercultural a través de la literatura. Espéculo. Revista de Estudios Literarios, Madrid, n. 32, 2006. Disponible en:

http://www.ucm.es/info/especulo/numero32/aprendiz.html. Accedido el: 3 oct. 2007.

LÓPEZ VÁZQUEZ, L. La competencia fraseológica en los textos de los manuales de ELE de nivel superior. In: Santiago-Guervós, J. (coord.). La aplicación de los textos a la enseñanza-aprendizaje del español L2-LE. [Madrid]: Asociación para la Enseñanza del Español como Lengua Extranjera, 2011. p. 531-542. Disponible en: https://dialnet.unirioja.es/servlet/libro?codigo=583797. Accedido el: 20 abr. 2018.

MADRID. Ministerio de Educación, Cultura y Deporte. Subdirección general de cooperación internacional, para la edición impresa en español. Marco Común Europeo de Referencia para las lenguas: aprendizaje, enseñanza, evaluación. Madrid: Ministerio de Educación, Cultura y Deporte, 2002. Disponible en:

https://cvc.cervantes.es/ensenanza/biblioteca_ele/marco/cvc_mer.pdf._Accedido el: 13 nov. 2010.

MARTÍ SÁNCHEZ, M. Explorando la definición real de los fraseologismos. CÍRCULO de Lingüística Aplicada a la Comunicación (clac), Madrid, n. 24, p. 1-27, 2005. Disponible en: http://www.ucm.es/info/circulo/no24/marti.htm. Accedido el: 12 oct. 2007.

PAIVA, R. S. C. de. Discussão do texto literário como ferramenta de ensino de E/LE em disciplinas do curso de Letras-Espanhol: propostas de componente curricular. Diálogo das Letras, Pau dos Ferros, v. 8, n. 3, p. 140-156, set./dez. 2019. Disponible en: http://periodicos.uern.br/index.php/dialogodasletras/article/view/4127/2077. Accedido el: 25 feb. 2021. 
RUIZ GURILLO, L. Un enfoque didáctico de la fraseología española para extranjeros: aprendizaje y enseñanza de una segunda lengua. In: COPERÍAS, M. J.; REDONDO, J.; SANMARTÍN, J. (ed.). Aprendizaje y enseñanza de una segunda lengua: quaderns de filologia. València: Universitat de València, 2000. p. 259-275.

SARACHO ARNÁIZ, M. La fraseología del español: una propuesta de didactización para la clase de ELE basado en los somatismos. 2015. 418 p. Tesis (Doctorado en Linguística) - Universidad de Santiago de Compostela, Santiago de Compostela, 2015. Disponible en: https://minerva.usc.es/xmlui/bitstream/10347/13585/1/rep 880.pdf. Accedido el: 10 dic. 2015.

SITMAN, R.; LERNER, Y. La literatura del mundo hispanohablante en el aula de E/LE: ¿un lugar de encuentro o desencuentro? Espéculo. Revista de Estudios Literarios, Madrid, n. 12, 1999. Disponible en: http://www.ucm.es/info/especulo/numero12/cbelatxt.html. Accedido el: 3 oct. 2007.

SOCORRO, M. V. El conocimiento sociocultural en los cursos de E/LE. In: SIMPOSIO INTERNACIONAL DE COMUNICACIÓN SOCIAL, 9., 2005, Santiago de Cuba. Anais [...]. Santiago de Cuba: Centro de Lingüística Aplicada, 2005. p. 765-767.

SOLER PUIG, J. Mercado libre. In: GRAJALES MELIAN, I. G.; RAMÍREZ CASTELLANOS, R. (org.). Narraciones en el tiempo: Panorama de la cuentística santiaguera (18312015). Santiago de Cuba: Ediciones Caserón, 2015. p. 193-198.

SZYNDLER, A. La fraseología en el aula de E/LE: ¿un reto difícil de alcanzar? una aproximación a la fraseodidáctica. Didáctica: Lengua y Literatura, Madrid, v. 27, p. 197216, 2015. Disponible en: http://dx.doi.org/10.5209/rev DIDA.2015.v27.50867. Accedido el: 20 abr. 2018.

TAVARES, A. J. Idiomatismos na sala de aula: uma proposta didática para o desenvolvimento da competência fraseológica. 2017. Dissertação (Mestrado Profissional em Letras Estrangeiras Modernas) - Universidade Estadual de Londrina, Londrina, 2017. Disponível em: https://meplem.com.br/wpcontent/uploads/2019/04/TAVARES ANDREIA-JARDIM.pdf. Acesso em: 5 fev. 2019.

TIMOFEEVA TIMOFEEV, L. La fraseología en la clase de lengua extranjera: ¿misión imposible? Onomázein, Santiago de Chile, n. 28, p. 320-336, 2013. Disponible en: http://onomazein.letras.uc.cl/Articulos/N28/28-24 Timofeeva FINAL.pdf. Accedido el: 10 dic. 2015.

VILLAVICENCIO SIMÓN, Y.; GRAJALES MELIAN, I. G. Apuntes para el desarrollo de la competencia léxica a través del uso de cuentos literarios en ELE. In: SIMPOSIO INTERNACIONAL DE COMUNICACIÓN SOCIAL, 11., 2009, Santiago de Cuba. Anais [...]. Santiago de Cuba: Centro de Lingüística Aplicada, 2009. p. 607-610.

VILLAVICENCIO SIMÓN, Y.; GRAJALES MELIAN, I. G. Premisas en torno a la programación de actividades para el estudio de los fraseologismos en las clases de español como lengua extranjera en la Universidad de Oriente. Santiago, Santiago de las Vegas, n. 124, p. 37-49, 2012. Disponible en: 
https://santiago.uo.edu.cu/index.php/stgo/article/view/1474/1448. Accedido el: 23 oct. 2013.

VILLAVICENCIO SIMÓN, Y.; TARDO FERNÁNDEZ, Y. La formación de la competencia fraseológica en la enseñanza del español como lengua extranjera: tratamiento a las colocaciones verbales. Ciencia e innovación tecnológica. [S. I.]: Académica Universitariarevista Opuntia Brava, v.2, 2018.

Submetido em: 06 mar. 2021. Aceito em: 06 jul. 2021. 